\title{
EL CALADO DE UNA VIDA ACADÉMICA
}

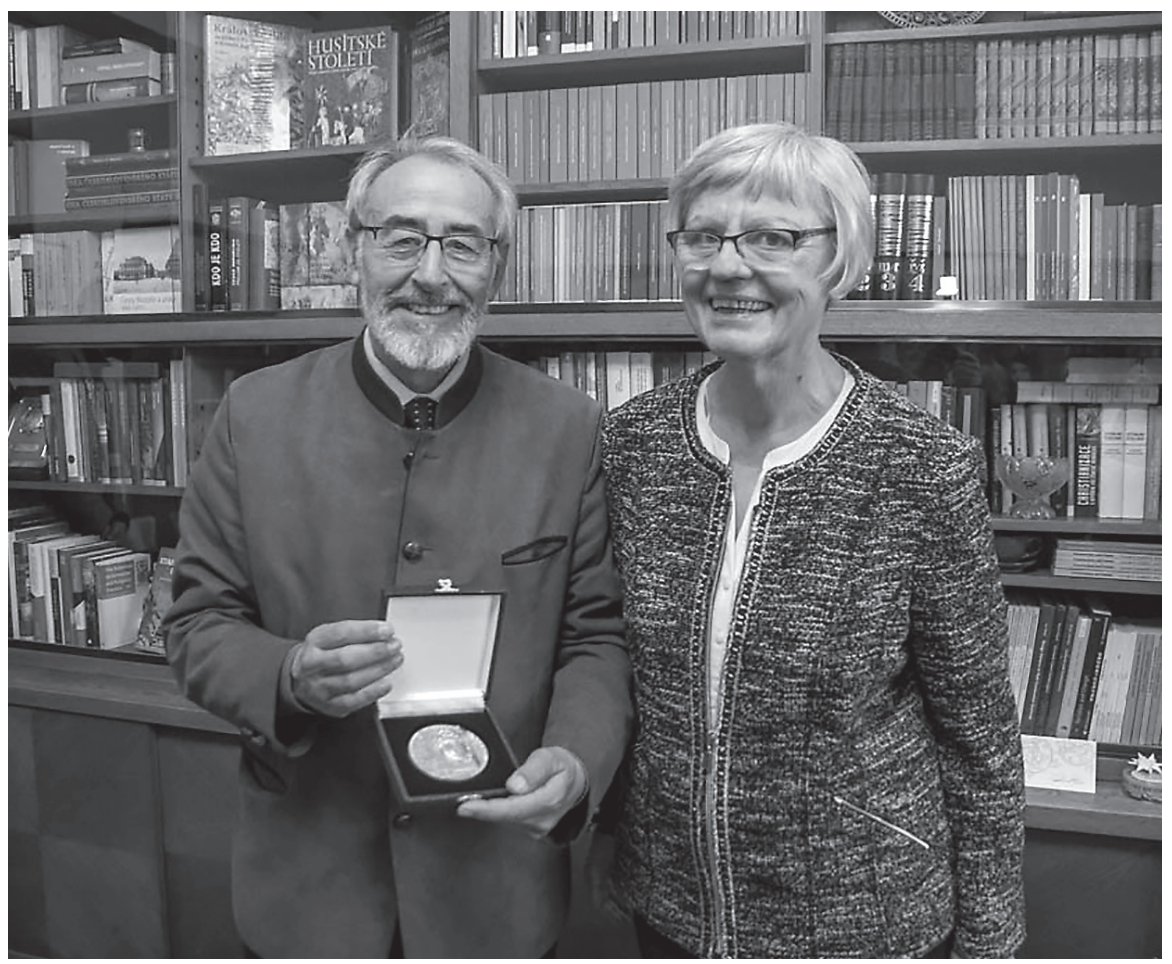

Profesores Miguel Ángel Vega y Jana Králová. Fuente: https://www.ff.cuni.cz/2018/01/prof-vega -cernuda-prevzal-stribrnou-pametni-medaili-filozoficke-fakulty-uk.

Suele ser bastante sencillo destacar los logros alcanzados por personas que muestran gran dedicación a una meta durante toda una vida. En tales casos, suelen abundar los ejemplos de su buen proceder que podemos mencionar. Sin embargo, al pensar en Miguel Ángel Vega se nos presenta una complicación a esta sencillez que preveíamos. Tal contratiempo no es otro que condensar en unas pocas páginas una trayectoria académica y personal tan extensa y de tanto calado como la suya, sin hablar de la diversidad de los ámbitos intelectuales visitados durante dicha trayectoria.

Si comenzáramos a escribir aquí al uso clásico el currículo de Miguel Ángel Vega Cernuda, empezaríamos diciendo que es traductor de alemán, danés, francés e italiano. Ha sido catedrático en la Universidad Complutense de Madrid y director 
del Instituto de Lenguas Modernas y Traducción de dicha Universidad y después catedrático de Traducción en la Universidad de Alicante. Aun después de jubilarse sigue dando conferencias en varias universidades europeas y latinoamericanas, es doctor honoris causa de la Universidad Ricardo Palma en Perú.

Sería sin embargo simplificar en exceso sus proyectos y sus afanes. Deberíamos pues intentar desglosar sus distintas facetas intelectuales y personales, para asimilar mejor la frondosidad de su trayectoria académica.

En primer lugar, nos interesa especialmente su faceta de traductor. Ha vertido al español numerosas obras, en especial a partir de la lengua alemana, aunque también del francés, el italiano o el danés. Podríamos repartir sus obras traducidas en cuatro grupos principales. ${ }^{1}$ En primer lugar, las traducciones del novelista y dramaturgo austriaco Arthur Schnitzler. Mencionemos de ellas la última publicada "En busca de horizontes" (Madrid: Cátedra, 2009). Otro conjunto de traducciones que podemos destacar es la dedicada a la literatura de viajes, en la que se recogen distintos relatos escritos por extranjeros visitando tierras españolas. Hay traducciones del italiano, francés y alemán. De este conjunto citaremos "Relación del viaje de España de Marie Catherine le Jumelle de Barneville, Baronesa d'Aulnoy" (Madrid: Cátedra, 2000). No elude Miguel Ángel Vega la dificultad de verter obras filosóficas. Así, hoy podemos acercarnos en español a la obra de Sloterdijk, gracias a sus traducciones Crítica de la Razón Cínica (Madrid: Siruela, 2003) e Ira y tiempo (Madrid: Siruela, 2010), junto a Elena Serrano Bertos. No podemos cerrar esta faceta sin citar el último apartado de su actividad traductora, la traducción de clásicos de la lengua alemana, como Bertold Brecht, mencionemos Poemas eróticos (Madrid: Visor, 1999), o el austriaco Ödön von Horváth, del cual referiremos Historias de los bosques de Viena. El divorcio de Fígaro (Madrid: Cátedra, 2008). Incluyamos aquí una prolífica labor de traducción de textos cortos, muchos de ellos publicados en la conocida revista sobre la traducción Hyeronimus Complutensis.

Sin duda alguna, su labor investigadora ha ocupado una gran parte de su vida profesional. Nos gustaría aquí destacar, tanto por su importancia para la Traductología como por su cercanía en el tiempo, el estudio de la traducción monacal y misionera en distintos ámbitos territoriales (Europa, Américas), a menudo en colaboración con compañeros del grupo de investigación HISTRAD. Nos es especialmente interesante y agradable la dedicación que Miguel Ángel ha puesto en la Traductología checa y su contribución para dar a conocer a Jiří Levý, figura de primer orden en los estudios de traducción, al lector hispanohablante. Así, ha colaborado en actividades académicas checas para difundir la obra de este traductólogo checo pionero, pero sobre todo fue el primero en verter parte de la obra de Levý (El arte de traducir) al español, hace ya más de 20 años. En concreto, esto sucedía en 1994, en Textos clásicos de teoría de la traducción publicado por la editorial Cátedra en Madrid. ${ }^{2}$

Pino VALERO, in: Martino Alba et al. (eds.), Al humanista, traductor y maestro Miguel Ángel Vega Cernuda, Madrid 2012, pp. 47-59.

2 Nuestro más sincero agradecimiento a Pilar Martino Alba por la bibliografía de publicaciones de M. A. Vega y otro material de referencia facilitados, así como por su gran disponibilidad. 
Su colaboración con el Instituto de Traductología praguense remonta a esa época. Un período en el que tanto la sociedad como la universidad checa se repensaban, se transformaban y, con ellas, la percepción y organización de las disciplinas académicas. Adelantándose a España y a otros países europeos, la Traductología checa se había emancipado de la Filología ya en los años 60, al menos en el organigrama universitario. A principios de los 90, pasó de ser cátedra a instituto de la Facultad de Filosofía. En este contexto es cuando se inicia la relación tan especial de Miguel Ángel con el Instituto checo, que se manifestará en múltiples proyectos y actos académicos, tanto en España como en la República Checa.

Como organizador de los Encuentros Complutenses en torno a la traducción abrió las puertas a contactos con el Instituto de Traductología y la Facultad de Filosofía y Letras en general, que desembocaron en publicaciones, participación en tribunales de tesis, convenios ERASMUS con diferentes Universidades Españolas, permitiendo hoy en día satisfacer el cien por cien de la demanda por parte de los alumnos, así como contactos con otros centros de investigación del mundo hispanohablante: citemos como ejemplo la revista colombiana Mutatis mutandis, en cuyo número monotemático dedicado a Jiří Levý contribuyeron no solamente los investigadores de los Institutos de Traductología y de Estudios Románicos, sino también de otros centros de la Facultad de Filosofía y Letras y de otras universidades checas y extranjeras. Ha impulsado también la presentación de información sobre los traductores checos en la biblioteca virtual Cervantes, en forma de seminarios optativos con los alumnos del máster en traducción del Instituto de Traductología.

Los trabajos del profesor Vega fueron publicados en la serie Translatologica Pragensia, contribuyó a la monografía Posibilidades y límites de la comunicación intercultural (=Iberoamericana Pragensia, Supplementum 27/2011), a la preparación de la antología Jiř́ Levý: una concepción (re)descubierta (J. Králová, M. Cuenca Drouhard, Soria, 2013), monografía de excelencia de la Universidad Carolina.

Durante el año académico 2012-2013 dedicó al Instituto de Traductología su año sabático, durante el cual atendió a los alumnos del máster y del doctorado en la elaboración de sus trabajos de máster, tesis doctorales y trabajos de investigación. La colaboración del profesor Vega con el Instituto continuó también después de su regreso a España: fue oponente de la tesis doctoral de Miguel Cuenca, asistió en la elaboración de los antologías estudiantiles Sedm tvář́ translatologie, Překlad a tlumočení jako most mezi dvěma břehy [Siete caras de la traductología, Traducción e interpretación como puente entre dos orillas] y en la preparación de la tesis de la PhDr. Petra Mračková Vavroušová, Ph.D., y Antonio Rivas González (†2017), alumno de doctorado en Traductología, con quien preparó la nueva edición crítica de Povídky malostranské [Cuentos de Malá Strana] de Jan Neruda (Cátedra, 2017). $\mathrm{Su}$ actividad no ha terminado y sigue preparando nuevos proyectos editoriales, en los que cuenta con la colaboración de los especialistas de la Facultad de Filosofía praguense.

Por último, desearíamos poner de relieve el lado humano de Miguel Ángel, su personalidad que hace posible conjugar todas estas facetas en una misma persona y al mismo tiempo transmitir "buenas vibraciones" a quienes lo rodean. Miguel Ángel tiene ese don pedagógico de transmitir su extenso saber sin abrumar al que escucha, 
de motivar a la inquietud intelectual sin mencionarla, aguijoneando la emulación del modo más discreto. Casi se diría que empuja sin querer a alumnos y compañeros a seguir adelante, a perseverar en la tarea y en buscar nuevas rutas que descubrir, del modo más natural. En definitiva, es un comunicador nato, un gran conversador, con una especial facultad de lograr la proximidad de quienes lo rodean. Evocan los alumnos de Traductología los consejos tan atinados que recibieron de Miguel Ángel cuando planeaban y redactaban sus distintos trabajos académicos. Recuerdan estudiantes y profesores que han tenido la ocasión de disfrutar de una agradable charla con Miguel Ángel durante un paseo por las calles y plazas de Praga, cómo los asuntos de la Traductología dejaban paso regularmente a comentarios sobre Historia del Arte, Música o Literatura inspirados por el sugerente entorno de la capital bohemia. Una conversación en la que Miguel Ángel seguro ha recurrido a su extensa y meditada cultura, una vez más, sin intimidar al compañero de paseo, sino usándola para espolear un diálogo que va ganando en interés al ritmo de los pasos. Al finalizar al paseo muchas son las ideas planteadas, los proyectos evocados, los acontecimientos rememorados. Pero, sobre todo se despide el acompañante del paseo con el convencimiento de haber encontrado un profesor, un compañero y, además, un amigo.

Así pues, no nos queda más que enviarle desde aquí nuestra felicitación por la merecida Medalla de Plata otorgada por la Facultad de Filosofía de la Universidad Carolina de Praga a Miguel Ángel Vega Cernuda y a través de la cual la institución y todos los que en ella hemos tenido el placer de colaborar con él queremos mostrar nuestro reconocimiento a su gran labor académica, así como por el inigualable estímulo personal e intelectual que ha representado a lo largo de los últimos años para alumnos y profesores del Instituto de Traductología. Gracias, Miguel Ángel.

por Miguel Cuenca (Praga) (Escrito en español por el autor) 